\title{
Colonization of Barley by the Broad-Host Hemibiotrophic Pathogen Phytophthora palmivora Uncovers a Leaf Development-Dependent Involvement of Mlo
}

\author{
Ruth Le Fevre, ${ }^{1}$ Bridget O’Boyle, ${ }^{1}$ Matthew J. Moscou, ${ }^{2}$ and Sebastian Schornack ${ }^{1}$ \\ ${ }^{1}$ Sainsbury Laboratory, University of Cambridge, Cambridge, U.K.; and ${ }^{2}$ The Sainsbury Laboratory, Norwich, U.K. \\ Submitted 21 December 2015. Accepted 21 February 2016.
}

\begin{abstract}
The discovery of barley Mlo demonstrated that filamentous pathogens rely on plant genes to achieve entry and lifecycle completion in barley leaves. While having a dramatic effect on foliar pathogens, it is unclear whether overlapping or distinct mechanisms affect filamentous pathogen infection of roots. To remove the bias connected with using different pathogens to understand colonization mechanisms in different tissues, we have utilized the aggressive hemibiotrophic oomycete pathogen Phytophthora palmivora. P. palmivora colonizes root as well as leaf tissues of barley (Hordeum vulgare). The infection is characterized by a transient biotrophy phase with formation of haustoria. Barley accessions varied in degree of susceptibility, with some accessions fully resistant to leaf infection. Notably, there was no overall correlation between degree of susceptibility in roots compared with leaves, suggesting that variation in different genes influences host susceptibility above and below ground. In addition, a developmental gradient influenced infection, with more extensive colonization observed in mature leaf sectors. The mlo5 mutation attenuates $P$. palmivora infection but only in young leaf tissues. The barley-P. palmivora interaction represents a simple system to identify and compare genetic components governing quantitative colonization in diverse barley tissue types.
\end{abstract}

Filamentous pathogens are responsible for major diseases that pose a constant threat to worldwide crop production (Fisher et al. 2012). Economically important monocot crops such as barley and wheat are colonized by fungal leaf pathogens, including Blumeria spp. (powdery mildews) and Puccinia spp. (rusts) as well as Zymoseptoria tritici (septoria leaf blotch) and the root-killing Gaeumannomyces graminis (take-all).

Deployment of new monocot crop resistances is often based on introgression of single or a few dominant disease resistance $(R)$ genes into established high-yielding crop varieties. While single $R$ gene-based resistance has provided some grace from pathogen attack, it is not a durable solution (McDonald and Linde 2002). Emerging aggressive isolates of filamentous pathogens, such as wheat stem rust Ug99, that overcome established resistances (Pretorius et al. 2000) highlight the need for alternative strategies.

Corresponding author: S. Schornack;

E-mail: sebastian.schornack@ slcu.cam.ac.uk

*The $\boldsymbol{e}$-Xtra logo stands for "electronic extra" and indicates that ten supplementary figures and four supplementary tables are published online. under the CC BY Attribution 4.0 International license.
Fundamental research in crop plants has demonstrated that filamentous pathogens rely on structural and biochemical plant properties to achieve entry and multiplication (Chen et al. 2010; Eichmann et al. 2010, 2004; Schultheiss et al. 2002; Wang et al. 2012). Removal of pathogen-essential plant genes (termed susceptibility genes) can provide long-lasting resistance (van Schie and Takken 2014). This has been shown through mutation of MLO, a member of a seven-transmembrane protein family, that provides barley with resistance to all races of powdery mildew fungus and is also essential for wheat powdery mildew (Büschges et al. 1997; Elliott et al. 2002; Wang et al. 2014). However, resistance principles based on loss-of-susceptibility may impact differently on other pathogens. Work with barley mlo mutants has revealed increased susceptibility toward Magnaporthe oryzae and Ramularia collo-cygni (Jarosch et al. 1999, McGrann et al. 2014) and sensitivity to toxins from Cochliobolus sativus (Kumar et al. 2001). Besides its role in the barley leaf epidermis, Mlo plays a role in root cortex colonization by mycorrhizal fungi (Ruiz-Lozano et al. 1999). Often it is unclear whether an identified loss-of-susceptibility to a pathogen in leaves would also be effective in roots.

So far, only a few fungal systems permit investigations in both above and below ground tissues of specific monocot species, and they are all natural leaf pathogens (Marcel et al. 2010; MazaheriNaeini et al. 2015; Sukno et al. 2008). Phytophthora palmivora, a member of the fungus-like oomycetes, has a broad host range and is adapted to diverse host and tissue environments. $P$. palmivora infects leaves (Forsberg 1985; Torres et al. 2010) and roots (Harris et al. 1984) of monocots and dicots (Rey et al. 2015; Wang et al. 2012) and causes important plant diseases including oil palm bud and stem rot, pod rot of cocoa, and root rot of papaya (Drenth and Guest 2004; Erwin and Ribeiro 1996). Similar to biotrophic fungi, $P$. palmivora initially requires living plant tissue to establish an infection. At this stage, $P$. palmivora forms intracellular digit- or peg-like haustoria (Harris et al. 1984; Rey et al. 2015) that project into plant cells to interfere with host cell immunity (Ellis et al. 2009; Hok et al. 2010; Kemen et al. 2005; Rafiqi et al. 2010) and to acquire nutrients (Harrison 1999). In the subsequent necrotrophic phase, the pathogen kills the host tissue to allow for efficient acquisition of nutrients for production of numerous mobile asexual zoospores. At this stage, $P$. palmivora does not depend on living host tissue anymore. By contrast to obligate biotrophic fungal pathogens, it is possible to easily cultivate Phytophthora on nutrient agar and to transform it with fluorescent proteins (Huitema et al. 2011; Rey et al. 2015) making it an attractive system for laboratory studies.

We utilized the aggressive hemibiotrophic oomycete pathogen $P$. palmivora to investigate colonization mechanisms in different barley tissues. Barley accessions vary in their degree 
of susceptibility to $P$. palmivora infection and there is no correlation between susceptibility in above- and below-ground tissues. This indicates that different genetic components underlie resistance in shoots and roots. In leaves, we found that developmental status of the tissue contributes to the degree of susceptibility and the extent of colonization. Furthermore, we

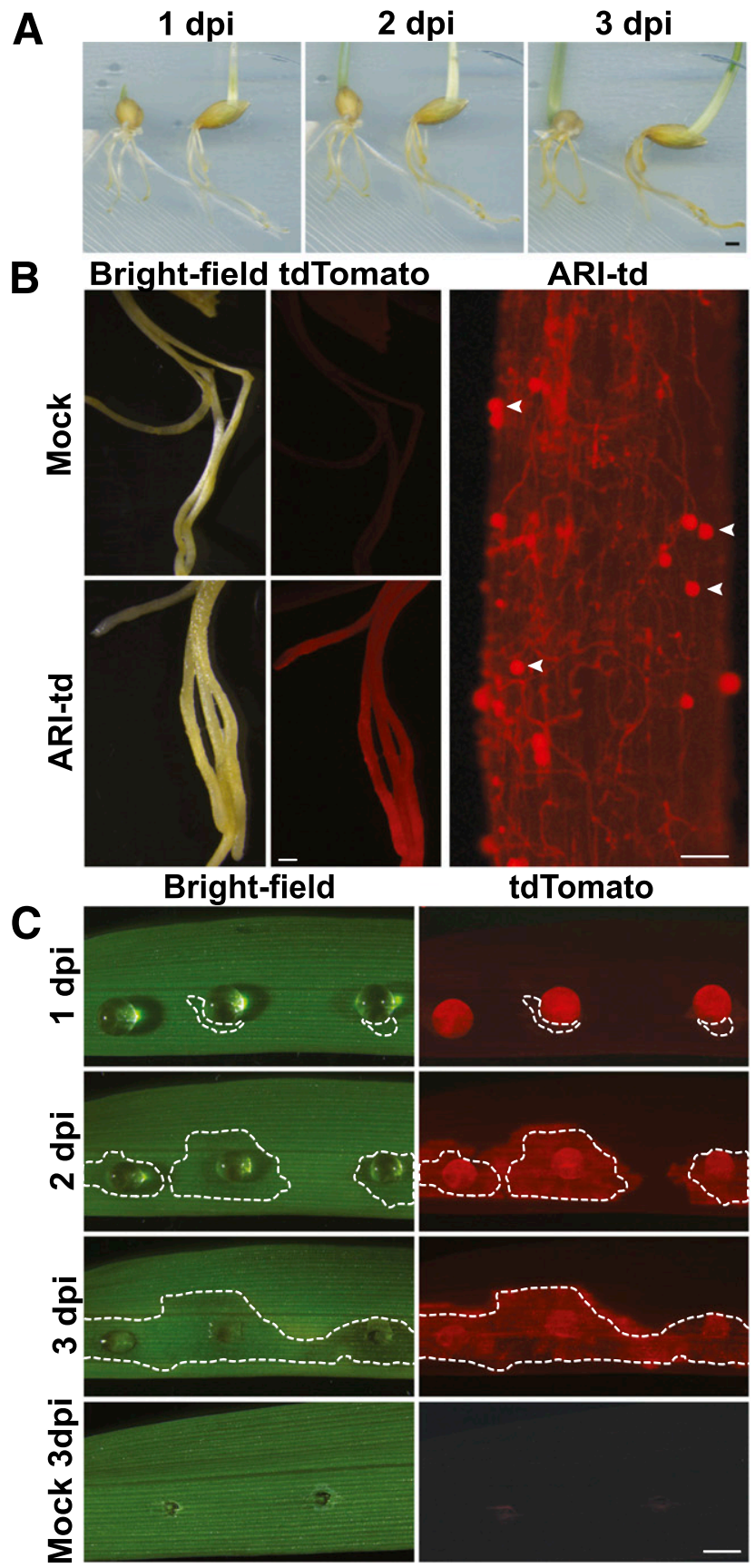

Fig. 1. Phytophthora palmivora colonizes roots and leaves of barley plants. A, Roots of cv. Baronesse barley seedlings inoculated with $P$. palmivora ARI zoospores. Representative development of root browning is shown at 1 to 3 days postinoculation (dpi). Scale is $2 \mathrm{~mm}$. B, Left, cv. Baronesse barley seedling roots, observed using epifluorescence microscopy for ARI-td infection in comparison with mock-inoculated roots at $3 \mathrm{dpi}$. Scale is $2 \mathrm{~mm}$. Right, magnified image of an infected root at $2 \mathrm{dpi}$. Scale is $0.25 \mathrm{~mm}$. White arrowheads indicate sporangia. C, Detached leaf sections from two-weekold cv. Baronesse barley plants inoculated with ARI-td zoospores. Representative stages of pathogen colonization at 1 to 3 dpi are shown. Scale is $2.5 \mathrm{~mm}$. ARI-td colonization extended further than visible symptoms suggested. White dashed lines in images at 1,2, and 3 dpi highlight the area that symptoms such as liquid-soaking were visible by eye. found that mlo5 mutant barley displays increased resistance in young leaf areas. In addition to these main findings, we propose that the reported barley root and leaf infection assays with $P$. palmivora represent a fast and efficient system to identify new genetic elements contributing to quantitative resistance. Genes discovered with this system might prove effective against economically important cereal pathogens, due to similarities in life stages shared with $P$. palmivora.

\section{RESULTS}

\section{Phytophthora palmivora colonizes leaves} and roots of barley.

$P$. palmivora is a filamentous oomycete pathogen with a broad host range that infects leaves and roots of monocot and dicot plants. To assess whether $P$. palmivora is capable of infecting barley roots and leaves, we established zoospore infection assays in these tissues. Roots of 4- to 5-day-old barley seedlings (cv. Baronesse) were inoculated with $P$. palmivora zoospores of various isolates (Supplementary Fig. S1; Supplementary Table S1). We monitored the development of rootbrowning symptoms over time and identified isolate ARI (P3914) as a suitable strain for barley root infection assays on the basis of its moderate aggressiveness (Fig. 1). P. palmivora ARI was transformed with a construct for constitutive expression of red fluorescent tdTomato (ARI-td) in the hyphal network. This allowed visualization and monitoring of accumulating red fluorescence and hyphal colonization in infected barley roots through fluorescence microscopy. Barley cv. Baronesse permitted profuse root colonization by ARI-td and the formation of sporangia was observed from 3 days postinoculation (dpi) (Fig. 1B). Assessment of $P$. palmivora biomass relative to barley biomass by quantitative reverse transcription-polymerase chain reaction (qRT-PCR) of PpEFl $\alpha$ showed a significant increase in biomass from $48 \mathrm{~h}$ postinoculation (hpi) onward (Fig. 2A), which correlated with increased root-browning symptoms (Fig. 1A; Supplementary Fig. S2B). The occurrence of sporulation was further supported by strong induction of $\mathrm{PpCdcl} 4$ (Fig. 2A), a sporulation-specific cell cycle marker (Ah Fong and Judelson 2003) at 72 hpi.

Since $P$. palmivora is capable of colonizing monocot leaf tissues such as the leaf bud of oil palm (Torres et al. 2010), we tested the ability of $P$. palmivora isolate ARI-td to infect detached barley leaves of cv. Baronesse. ARI-td infected pinpricked leaves but cannot enter unwounded leaves, on which it remains on the leaf surface (Supplementary Fig. S3). Profuse hyphal growth was observed in the mesophyll, as monitored by ARI-td red fluorescence, and accompanied the formation of expanding necrotic liquid-soaked areas (Fig. 1C). By contrast, pinpricking and application of droplets from control plates did not result in any observed changes (Fig. 1C). qRT-PCR quantification of PpEFl $\alpha$ showed a significant increase in biomass from $48 \mathrm{hpi}$ in roots and $\mathrm{PpCdcl} 4$ expression increased at $72 \mathrm{hpi}$, consistent with the observation of sporulation at this timepoint (Fig. 2B).

Taken together, $P$. palmivora ARI-td infects barley cv. Baronesse and colonizes root and wounded leaf tissues.

\section{P. palmivora exerts a hemibiotrophic lifestyle in barley.}

Most Phytophthora species are hemibiotrophs. During biotrophy, they colonize tissue without visible defense or disease symptoms and then switch to necrotrophy, resulting in tissue collapse. We noted that fluorescently labeled $P$. palmivora ARI-td hyphae extended asymptomatically into barley leaf tissue beyond the zone of visible tissue collapse and liquid-soaking (Fig. 1C), suggesting that the leading edges of ARI-td infection exhibit biotrophy. Biotrophy is commonly associated with appressoria at host tissue surface and haustoria inside host cells. 
Recently, $P$. palmivora has been reported to form appressoria and haustoria when colonizing Medicago truncatula roots (Rey et al. 2015; Wang et al. 2012). Microscopic inspection of $P$. palmivora ARI-td-infected barley cv. Baronesse roots revealed the formation of appressoria on the surface at $5 \mathrm{hpi}$ (Fig. 3). No appressoria were formed on leaves that were not pinpricked. From 28 to $48 \mathrm{hpi}$, we found numerous digit-like haustoria in both roots and leaves, suggesting that ARI-td establishes a biotrophic interaction in both tissues. This is supported by qRT-PCR data from root and leaf infection time courses (Fig. 2A and B). Expression levels of $P$. palmivora haustorium membrane protein 1 ( $\mathrm{PpHmpl)}$ were induced at timepoints up to 48 hpi in both tissues. PAL1, the $P$. palmivora homolog of $P$. infestans infl (Kamoun et al. 1997), was transcriptionally induced 48 and 72 hpi (Fig. 2A and B). We conclude that $P$. palmivora infection of barley roots and leaves is characterized by a transient biotrophic phase with formation of haustoria, followed by a necrotrophic phase during which sporulation occurs.

\section{Contribution of barley genetic variation}

to root and leaf colonization is not linked.

To assess whether genetic variation of the host contributes to the degree of susceptibility, we carried out root and leaf infection assays on 18 barley accessions encompassing domesticated varieties as well as diverse wild accessions from various origins (Fig. 4A; Supplementary Table S2). Using a scoring system based on root-browning intensity and hyphal spread in leaf mesophyll, we found variation in median disease scores ranging from 0.07 in roots in the quantitatively resistant landrace accession HOR 1428 to a median of 0.42 in the most susceptible cv. Haruna Nijo (Fig. 4B). Cv. Baronesse was found to be the most susceptible to leaf infection (median disease score 0.79), permitting unrestricted colonization of leaf mesophyll, with red

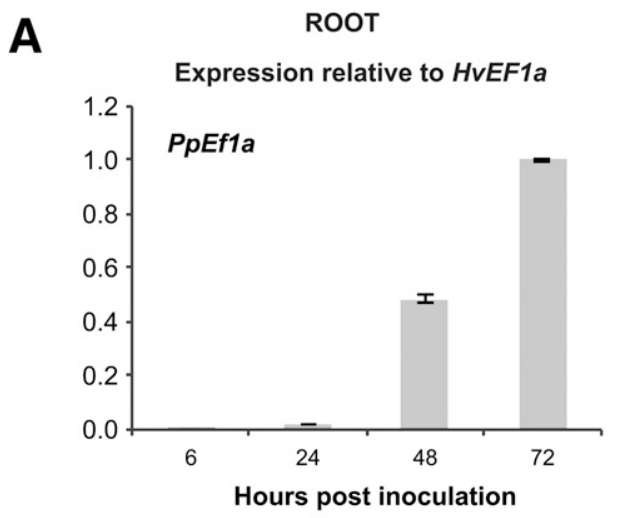

B
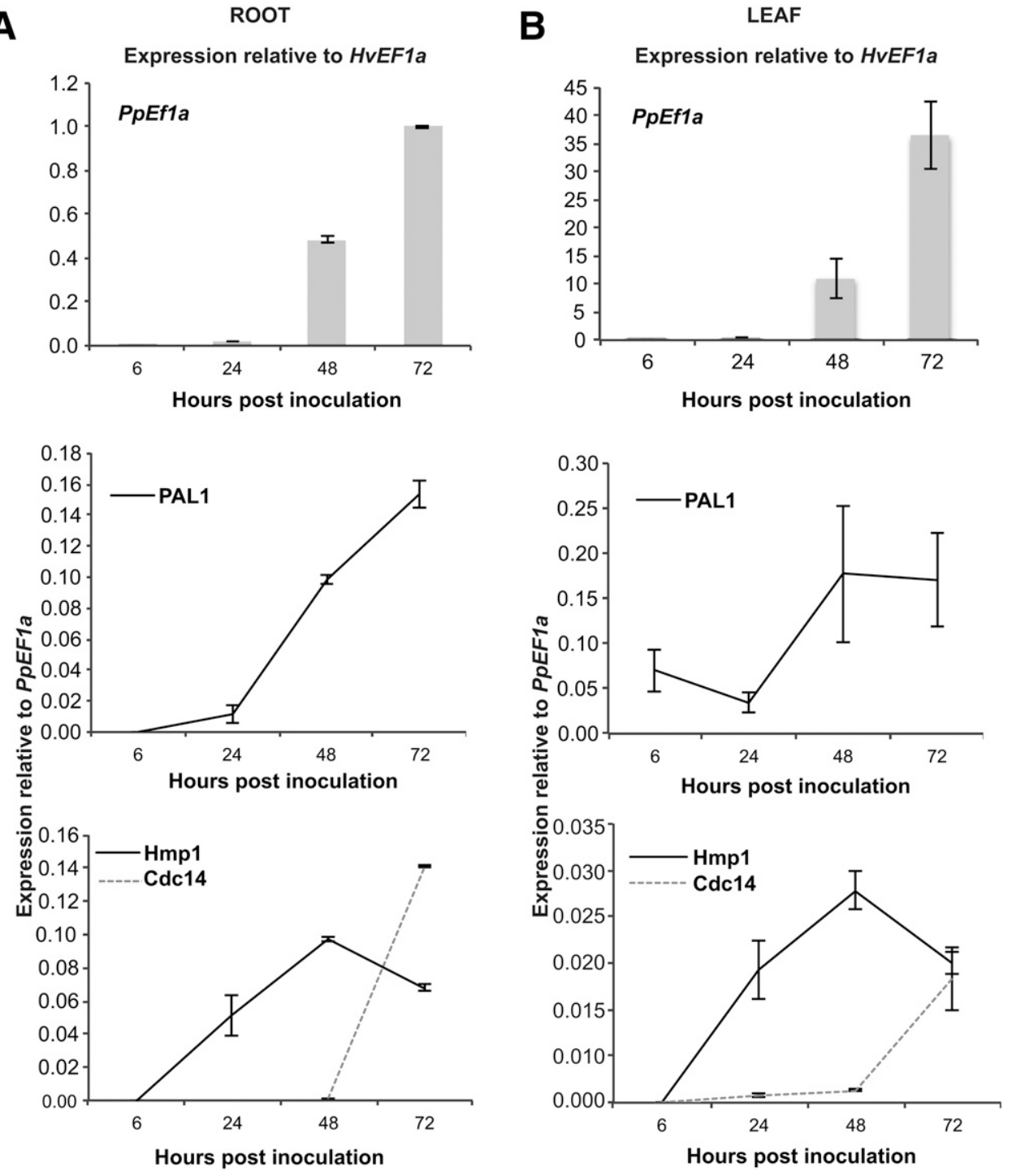

Fig. 2. Expression of life-stage marker genes during root and leaf infection by Phytophthora palmivora follow similar trends. A, ARI-td biomass accumulation over time in barley cv. Baronesse seedling roots was measured by expression of P. palmivora EFl $\alpha$ relative to Hordeum vulgare Efl $\alpha$. Expression of P. palmivora lifestyle marker genes PAL1, Hmpl, and Cdcl4 were measured over time relative to P. palmivora EF1 $\alpha$. Data shown are representative of two experiments, $n=12$ seedlings, the roots of which were pooled together per timepoint. Error bars are standard deviation calculated from triplicate quantitative polymerase chain reaction technical replicates. B, ARI-td biomass accumulation over time in first leaves of barley cv. Baronesse was measured by expression of P. palmivora EF $1 \alpha$ relative to $H$. vulgare Efl $\alpha$. Expression of P. palmivora lifestyle marker genes PAL1, Hmpl, and Cdc14 were measured over time relative to P. palmivora EF1 $\alpha$. Data shown are representative of two experiments, with three barley cv. Baronesse seedlings per timepoint. Error bars are standard error of the mean calculated from the three biological replicates. 
fluorescent $P$. palmivora ARI-td hyphae. Conversely, cv. Morex was the most resistant variety and did not support any pathogen growth in leaves (Fig. 4C). Infiltration of ink to the same area after pinpricking the leaf surface of different barley cultivars indicated that lack of access to the leaf mesophyll by the zoospore inoculation solution or altered intercellular space connectivity was likely not a reason for the differential colonization in leaves between resistant and susceptible accessions (Supplementary Fig. S4). Notably, there was no overall correlation between disease scores in roots and leaves in the tested accessions $\left(\mathrm{R}^{2}=0.04682\right)$, suggesting that variation in different genes influences host susceptibility above and below ground (Supplementary Fig. S5).

\section{$P$. palmivora leaf tissue susceptibility varies between and within leaves of different age.}

We next tested whether different leaves from the same plant varied for the degree of $P$. palmivora mesophyll spread. We inoculated ARI-td P. palmivora onto dissected leaf sections, from the base (meristem-proximal) and from toward the tip (meristem-distal), of the first leaf (oldest), second leaf, and third leaf (youngest) from two-week-old plants and microscopically assessed hyphal growth at 3 dpi. We did not observe significant differences in infection scores between distal sections of the different leaves, which all displayed high susceptibly (Fig. 5; Supplementary Table S4). However, the data indicated a trend of decreasing susceptibility in proximal

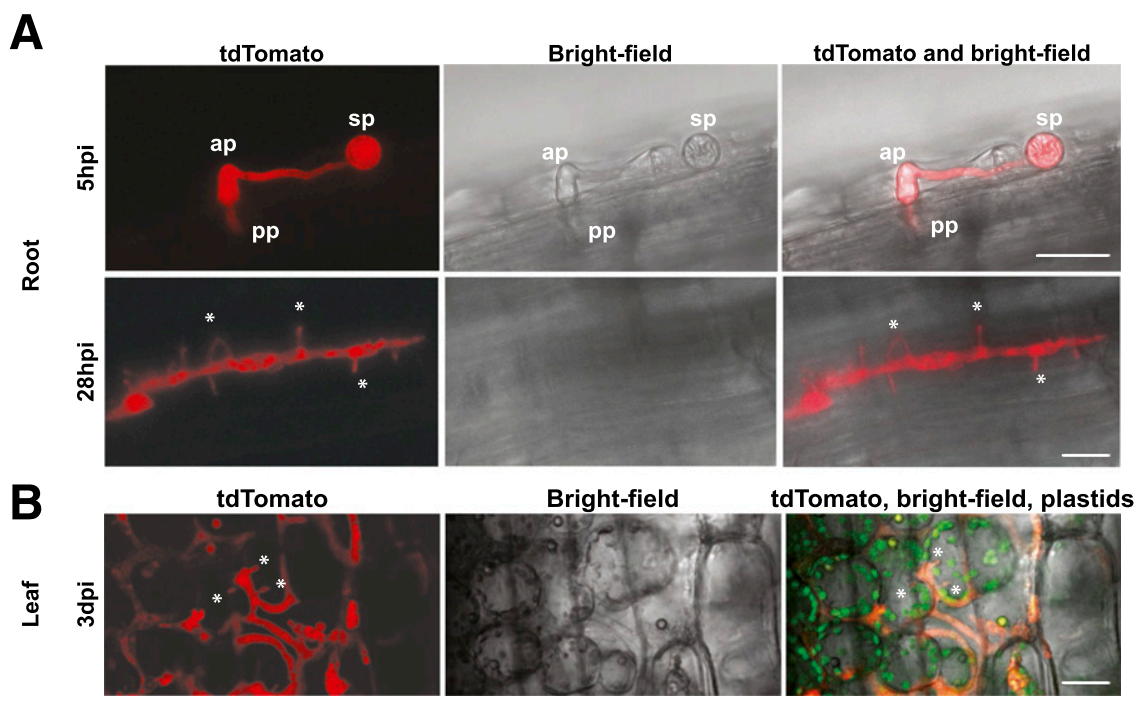

Fig. 3. Phytophthora palmivora ARI-td produces haustoria in roots and leaves of barley. A, Appressorium (ap) and penetration peg (pp) formation by ARI-td in barley cv. Baronesse root tissue at $5 \mathrm{~h}$ postinoculation (hpi) (spore [sp] is also marked) and haustoria formation at $28 \mathrm{hpi}$. Haustoria in the tdTomato images are highlighted by white asterisks. B, Haustoria produced by P. palmivora ARI-td in barley cv. Baronesse leaf tissue at 3 days postinoculation are indicated by white asterisks. Scale bars apply to all images and are $20 \mu \mathrm{m}$.
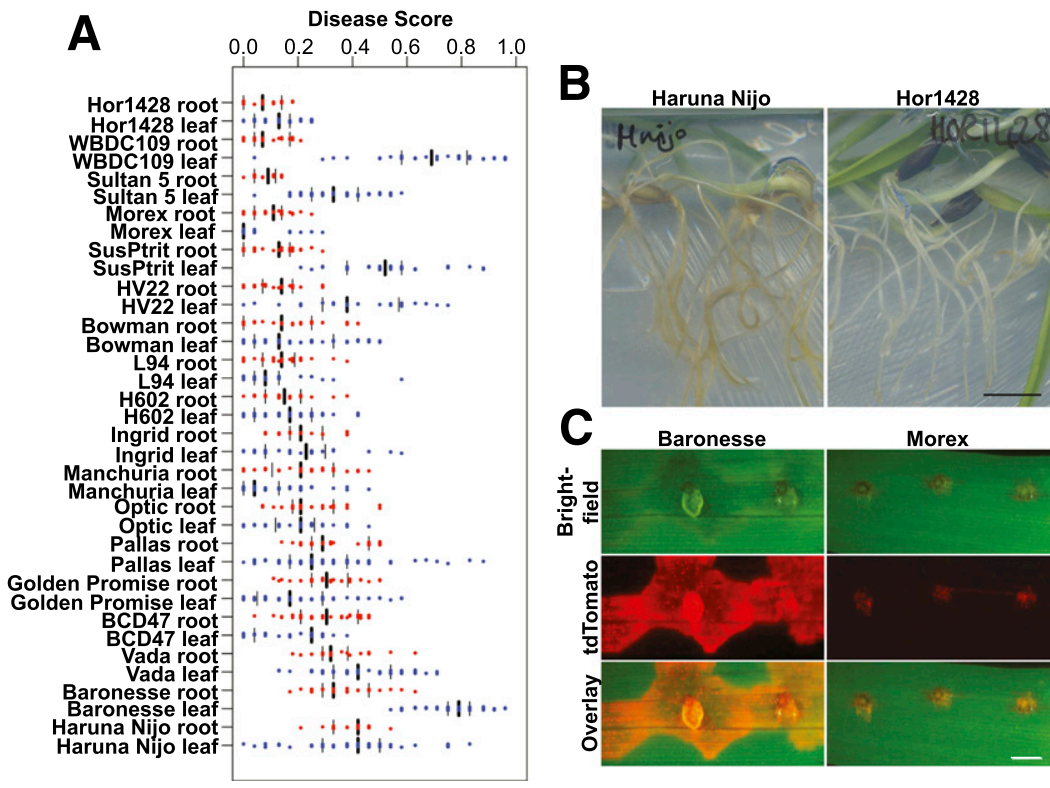

Fig. 4. Extensive genetic variation in resistance to Phytophthora palmivora ARI-td in roots and leaves of barley. A, Roots and the first leaves of 18 wild and cultivated barley lines were tested for resistance to P. palmivora ARI-td; $n=28$ to 90 plants per line for leaf assays and 16 to 36 plants per line for root assays. Data points for individual plants are plotted, blue for leaf assays and red for root assays. A thick black line indicates the median and thin black lines indicate the upper and lower interquartile ranges. B, Roots from most susceptible barley cv. Haruna Nijo in comparison with resistant wild accession HOR1428 at 6 days postinoculation (dpi). Scale bar is $1 \mathrm{~cm}$. C, Leaves of susceptible cv. Baronesse in comparison with resistant cv. Morex at 3 dpi. Scale bar applies to all images and is $3 \mathrm{~mm}$. 
sections from leaf one to leaf three and the susceptibility of the proximal section of the first leaf (most susceptible to $P$. palmivora mesophyll spread) was significantly different from that of the third leaf (most resistant to P. palmivora mesophyll spread [Fig. 5]). This also indicates differences in susceptibility between meristem-proximal and distal sections within each leaf and this was found to be highly significant in leaves two and three (Fig. 5A and B). To investigate whether the difference in susceptibility between proximal and distal leaf tissue was also present in a resistant barley variety, proximal and distal segments of first, second, and third leaves of the resistant cv. Manchuria were inoculated with ARI-td and were scored at 3 dpi. While no obvious visual difference was observed in degree of infection of proximal and distal tissue within leaves or between leaves (Supplementary Fig. S6B), the disease score data suggested similar trends to those seen for the susceptible variety. Additionally, statistical assessment indicated significantly higher infection in meristem-distal tissues of third leaves in comparison with their meristem-proximal counterparts. Therefore, the position-dependent susceptibility to ARI-td is present in both susceptible and more resistant varieties.

Focusing on cv. Baronesse, we next carried out inoculations at regular distances between meristem-proximal and meristemdistal leaf areas on whole-detached first, second, and third leaves. We observed proximal resistance and distal susceptibility to P. palmivora ARI-td by red fluorescence, as seen previously (Fig. 5C). ARI-td biomass in proximal (Supplementary Fig. S8B) and distal (Fig. 2B) leaf sections was quantified by qRT-
PCR. ARI-td biomass was up to $94 \%$ greater in distal leaf sections at 72 hpi than in proximal leaf sections. ARI-td biomass in areas in-between proximal and distal sections was not quantified but was identified by red-fluorescence, and pathogen colonization was found to gradually increase along the leaf, resulting in a gradient of susceptibility from proximal to distal tissue (Fig. 5C). Similar differences in position-dependent susceptibility were visualized in dissected whole leaves (Fig. 5B; Supplementary Fig. S7). Next, we tested whether $P$. palmivora adopts the same lifestyle in meristem-proximal versus meristemdistal leaf sections. Microscopic inspection of infected leaf tissues at 48 hpi revealed haustoria in both regions indicative of biotrophy. qRT-PCR analysis of $\mathrm{Hmpl}$ expression in ARI-td-infected meristem-proximal and meristem-distal (Fig. 2B) leaf sections was found to be comparably increased at 24 and 48 hpi, consistent with our findings of haustoria in both tissue regions within this time period (Fig. 2B) and with a biotrophy phase for the pathogen in both proximal and distal leaf tissue sections.

To assess whether there are pathogen strain-specific effects on establishment of the gradual differences in position-dependent susceptibility, we carried out leaf infections with $P$. palmivora isolates that showed different root aggressiveness (Supplementary Fig. S9). We observed minimal infection success with isolates STITCH (P0113), LANA (P3940), and FRED (P7547). All other tested $P$. palmivora isolates successfully colonized cv. Baronesse leaf tissue and showed establishment of an infection symptom gradient between meristem-proximal and distal leaf tissue.

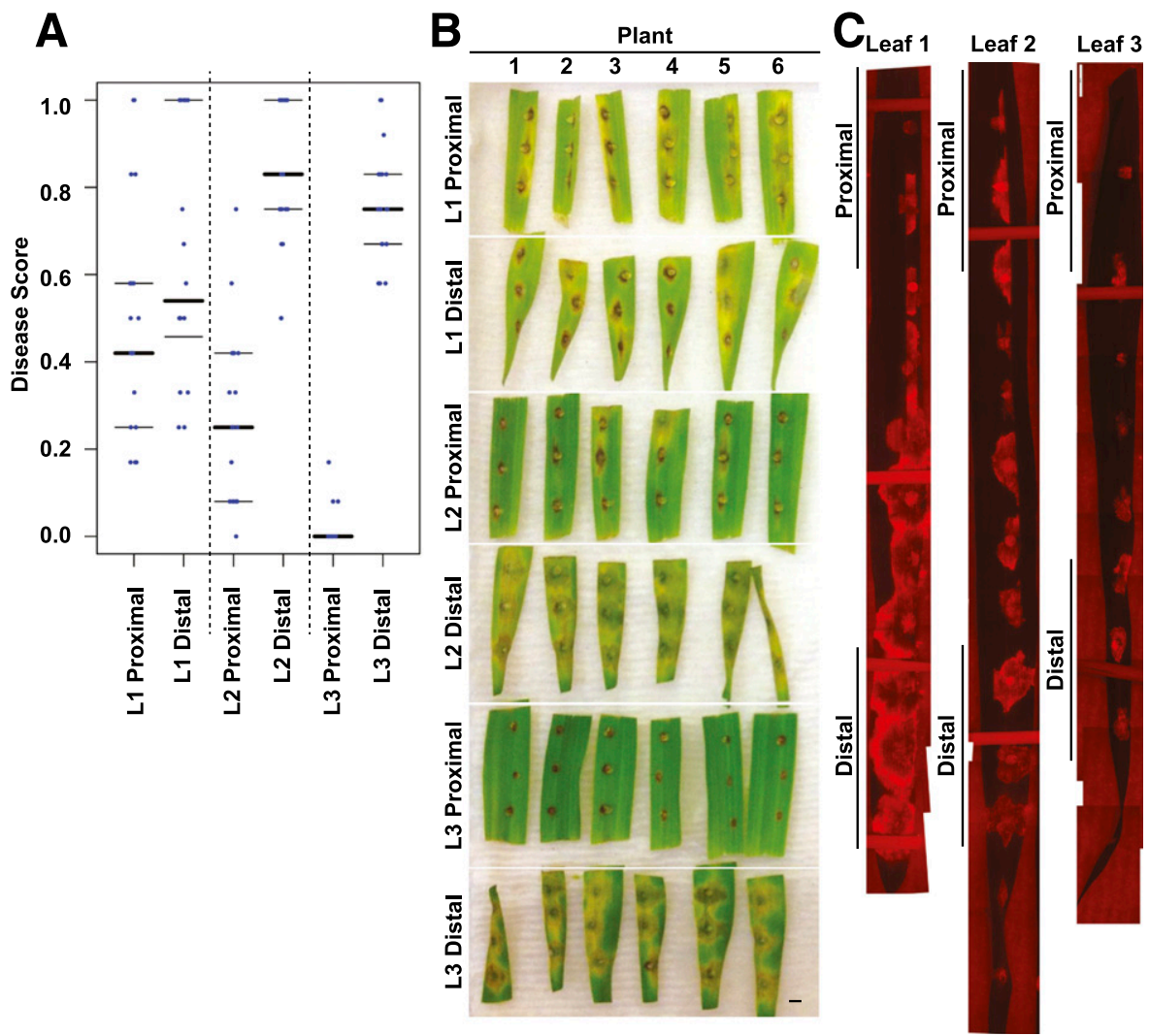

Fig. 5. Leaf position and leaf development contribute to susceptibility to Phytophthora palmivora. A, Dissected meristem-proximal and distal leaf parts were inoculated with $P$. palmivora ARI-td. Pictures were taken at 3 days postinoculation (dpi). Data points in blue are individual plants from five independent experiments, three to six plants per experiment. Median and interquartile ranges are indicated by thick and thin black lines, respectively. B, Representative pictures of barley cv. Baronesse leaf segments taken 3 dpi with ARI-td. Scale is $0.5 \mathrm{~cm}$. C, Whole first, second, and third leaves of 2-week-old barley plants were inoculated with ARI-td. tdTomato was detected at 3 dpi and pictures were taken with a dissecting epifluorescence microscope. Sequential images were taken of all inoculation spots, using the same microscopy settings. Brightness and contrast of all images was adjusted equally and images were tiled to give an overview of whole leaves. Scale (in white at the top of leaf three) is $1 \mathrm{~cm}$. 
In summary, we found that the extent of colonization in the leaf mesophyll is affected by the relative position of the infection along the leaf, with younger leaf parts and younger whole leaves being more resistant than older leaf parts and older leaves. In strongly resistant genotypes, leaf development and position have no effect on colonization ability of the pathogen, i.e., all tissues at all stages so far tested are resistant.

\section{Mlo expression is induced}

during $P$. palmivora colonization.

Mlo is a well-known susceptibility gene but its fundamental biochemical activity remains unknown. In barley, loss-of-function alleles confer broad-spectrum resistance to Blumeria graminis f. sp. hordei but can increase susceptibility to other filamentous pathogens (Jarosch et al. 1999; Jørgensen 1992; McGrann et al. 2014). Mlo expression is induced in barley leaves in response to challenges by both powdery mildew and $M$. oryzae (Piffanelli et al. 2002). To assess whether Mlo is also induced in response to $P$. palmivora, we conducted a time course experiment with mockinoculated and $P$. palmivora-inoculated susceptible first leaves of barley cv. Baronesse and analyzed the change in Mlo expression over time. P. palmivora infection in proximal and distal parts of the leaf resulted in higher Mlo expression levels compared with mock-inoculated tissue. Additionally, Mlo expression levels in distal infected tissue continued to increase from 24 hpi onward compared with those in proximal-infected tissue (Fig. 6A and B), in line with our observations that the extent of colonization is increasing over time in distal tissues but is restricted in proximal tissues (Fig. 5). Thus, in addition to the filamentous pathogens described previously, expression of Mlo in barley leaves is also responsive to the oomycete pathogen $P$. palmivora.

\section{Mlo contributes to leaf colonization.}

Given that Mlo expression is responsive to $P$. palmivora infection, we next tested whether loss of Mlo could impact resistance in barley leaves. Barley cv. Pallas was sufficiently susceptible to allow assessment of barley Mlo contribution to $P$. palmivora colonization. We compared leaf infections on isogenic barley cv. Pallas carrying wild-type (WT) Mlo and a Pallas backcross (BC) line carrying the mlo-5 mutation (Kølster et al. 1986). We found that mlo-5 BC Pallas leaves were significantly more resistant in meristem-proximal tissue in comparison with WT Pallas leaves, while meristem-distal tissues were similarly infected in both lines (Fig. 7A). Since mlo-5 BC Pallas mutants have been reported to develop spontaneous lesions (Peterhansel et al. 1997; Wolter et al. 1993), we also tested whether lesion formation was more frequently occurring in proximal tissues. Trypan blue staining of WT Pallas and mlo5 BC Pallas leaves revealed occurrences of punctate cell death but the distribution of lesions was not visibly changed along the leaves (Supplementary Fig. S10).

Mlo also contributes to colonization by arbuscular mycorrhizal fungi in roots (Ruiz-Lozano et al. 1999). To test whether susceptibility to $P$. palmivora was altered in mlo barley plant roots, we inoculated roots of Pallas and mlo5 BC Pallas seedlings with ARI-td. No significant difference in susceptibility was noted between these genotypes (Fig. 6B and D). We conclude that the contribution of Mlo to susceptibility of $P$. palmivora is confined to a specific leaf tissue developmental stage.

\section{DISCUSSION}

Here, we report the use of a broad host range, monocotand dicot-infecting oomycete pathogen to unravel common and contrasting levels of susceptibility within barley leaves and roots. We use fluorescently labeled $P$. palmivora to track infection progress in leaf and root tissue. We report a transient biotrophic phase in both organs, evident through the formation of haustoria and transient changes in biotrophy marker expression. Barley accessions responded differently to $P$. palmivora infection.
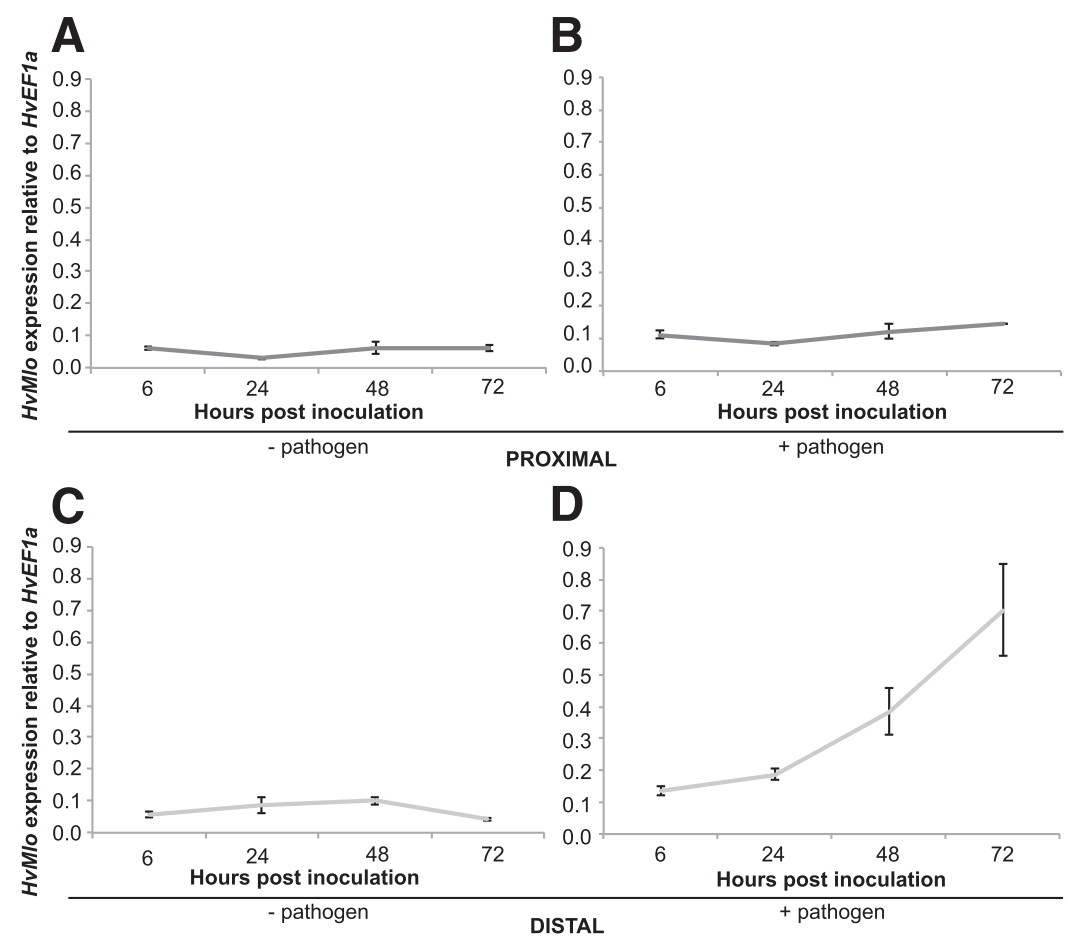

Fig. 6. Mlo expression is induced by Phytophthora palmivora challenge. A and C, First leaves form cv. Baronesse plants were detached and wounded at six equidistant points along the leaf and were mock inoculated with water or $\mathbf{B}$ and $\mathbf{D}$, were inoculated with spores of $P$. palmivora ARI-td. HvMlo expression was determined relative to $H v E F 1 \alpha$ expression. Proximal refers to the three spots nearest the cut end of the leaf while distal refers to the three spots nearest the tip. The -pathogen and +pathogen labels refer to mock- or pathogen-inoculated, respectively. Three first leaves from separate plants were used per timepoint per experiment. The experiment was repeated with similar results. Error bars are standard error of the mean. 
Notably, the degree of susceptibility of leaves and roots was unlinked, suggesting different genetic mechanisms underlying resistance in above- and below-ground tissues. In leaves, we found variation in resistance and susceptibility between first, second, and third leaves and also between meristem-proximal and meristem-distal sections of the same leaf blade. Furthermore, we provided evidence that barley Mlo plays a role in $P$. palmivora-barley leaf infection.

We observed quantitative rather than qualitative resistance in the interaction of $P$. palmivora with different barley accessions. Although it is unclear whether gene-for-gene resistance acts within this system, the quantitative differences observed between barley accessions may be due to a lack of coevolution between pathogen and host, as they have evolved independently in disparate geographical locations. It will be interesting to test whether other pathogens with quantitative resistance within barley and similar or divergent lifestyles to $P$. palmivora yield results similar to those presented here. In the future, genotypic variation of quantitative resistance toward $P$. palmivora could be utilized to identify underlying plant genetic components with impact on other quantitative filamentous plant-microbe interactions. Using $P$. palmivora to uncover more widely implied critical genetic components of filamentous plant-microbe interactions has previously been successful in dicots (Rey et al. 2015; Wang et al. 2012).

Filamentous biotrophic pathogens of cereal crops are predominantly tissue-specific; for example, isolates of the powdery mildew pathogen $B$. graminis exclusively infect the leaf epidermis. However, some leaf pathogens, such as M. oryzae, Ustilago maydis, and Colletotrichum graminicola, are able to infect both above- and below-ground tissues (Dufresne and Osbourn 2001; Mazaheri-Naeini et al. 2015; Sukno et al. 2008). One problem with using leaf pathogens for shoot-root comparisons is that they change their infection behavior significantly when forced to colonize roots (Marcel et al. 2010; Sesma and Osbourn 2004; Sukno et al. 2008). While interesting in itself, this can prevent or complicate direct comparisons between plant-microbe interactions in different organs. The $P$. palmivora-barley system is particularly suitable for organcomparative studies of biotrophy, as we have found it exerts a similar hemibiotrophic lifestyle in both leaves and roots (Figs. 2 and 3). One avenue for future research could include comparing infection between different plant organs with regards to the function of pathogen effector proteins. In the U. maydis-maize interaction, different effectors are reported to contribute to the colonization of different plant organs (Schilling et al. 2014). It will be interesting to assess whether this finding is linked to a varying lifestyle or also holds true for $P$. palmivora.

Given the obvious differences in environment and exposure to different microorganisms of roots and shoots, we can fully expect different mechanisms to underlie plant-microbe interactions above and below ground. Therefore, we hypothesize that assessing the degree of susceptibility of leaves is not sufficient to infer the root susceptibility status. Indeed, in Arabidopsis thaliana, leaves are resistant to $M$. oryzae while roots
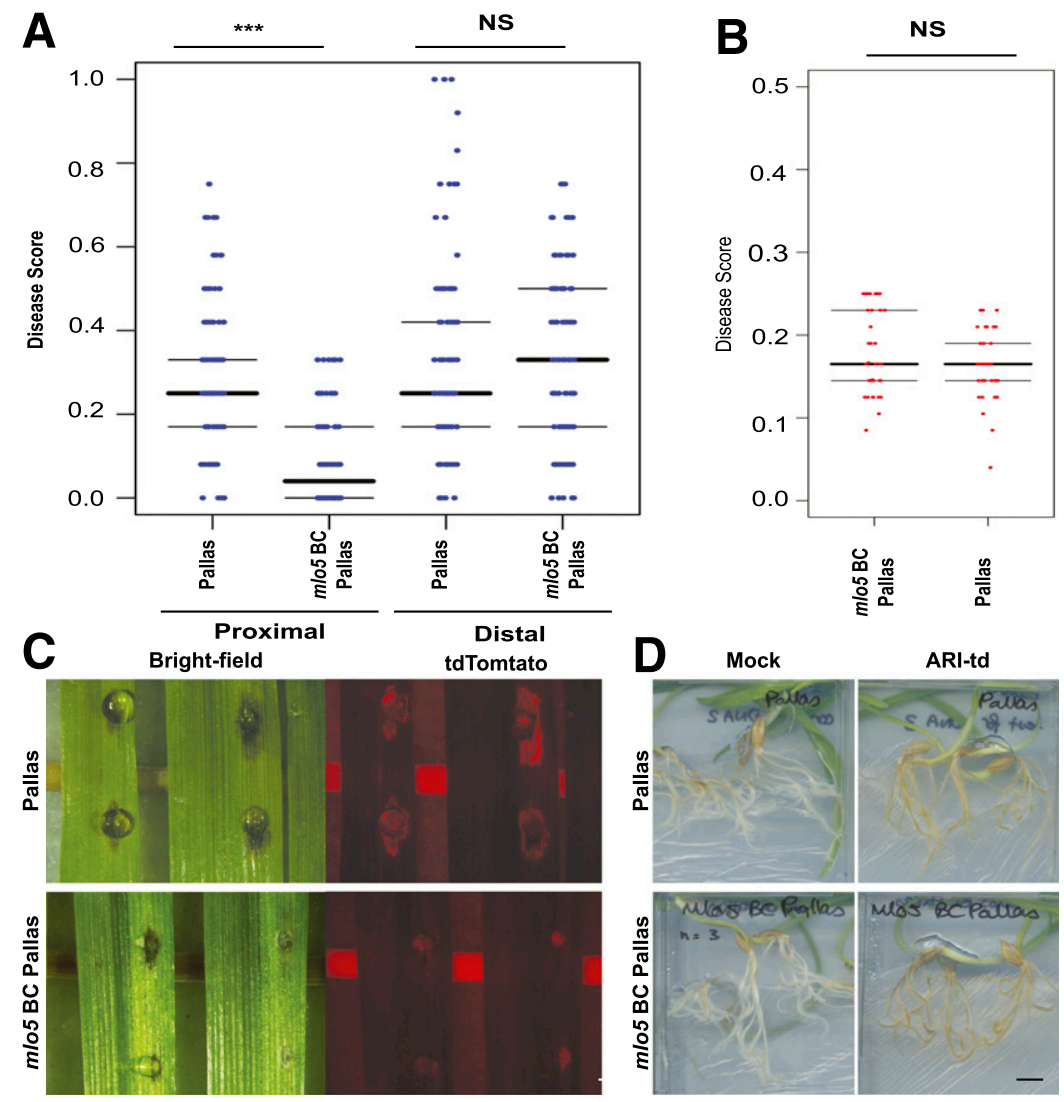

Fig. 7. Mlo contributes to resistance to Phytophthora palmivora colonization in leaves but not in roots. A, First leaves of 2-week-old cv. Pallas and mlo5 BC Pallas barley plants were inoculated at six equidistant points with zoospores of $P$. palmivora ARI-td. Extent of colonization was scored at 3 days postinoculation (dpi) in the proximal three spots and in the distal three spots. Individual data points from eight independent experiments are shown in blue and the median and interquartile ranges are indicated by thick and thin black lines, respectively, with a total 105 leaves per genotype. Scores in $m l o 5$ BC Pallas were tested for significant deviation from that of the Pallas control, using a two-sample Kolmogorov-Smirnov test (* indicates $P<0.05, * *, P<0.001$, and $* * *, P<0.0001$ ). B, Roots of 4-day-old cv. Pallas and mlo5 BC Pallas seedlings were inoculated with ARI-td and were scored for infection over six days. No significant difference was found between median disease scores of the genotypes. Data shown is pooled from three experiments, with 36 plants for Pallas and 41 for $m l o 5$ BC Pallas. C, Representative leaf pictures of the difference in proximal leaf colonization between Pallas and mlo5 genotypes are shown. Images were adjusted for contrast, scale bar is $2 \mathrm{~mm}$. D, Representative pictures of mock and ARI-td infected roots at 6 dpi are shown. Scale bar is $4 \mathrm{~mm}$. 
are susceptible (Schreiber et al. 2011). The data presented here are in agreement with this hypothesis, as we did not identify a correlation between $P$. palmivora susceptibility disease scores for above and below ground tissues despite similar hemibiotrophic lifestyles. Interestingly, the use of mutants has shown that defense components are generally conserved in above- and below-ground plant tissues (De Coninck et al. 2015). However, we can use our more in-depth knowledge of above-ground responses to filamentous microbes to compare and contrast the situation in roots. Further comparative transcriptomic and genetic studies could identify major genetic components governing these differences (Skibbe et al. 2010).

In our work, we observed that leaves of different ages form the same plant have different susceptibilities to $P$. palmivora. When the first, second, and third leaves from young plants were harvested and inoculated at the same time, the oldest (first) leaf was more susceptible than the younger following leaves (Fig. 5B). This mature tissue susceptibility (MTS) to $P$. palmivora was also visible within single leaves, in which mature meristemdistal tissues were more susceptible than young meristemproximal tissues (Fig. 5B and C). Similar differences were also observed in dissected whole leaves, indicating that this gradient is likely not relying on maintained proximal-distal transport processes (Fig. 5B). Although pathogen biomass was always less in younger leaf tissue sections than in mature tissue sections, we found evidence of biotrophy through detection of haustoria via microscopy and expression of the haustorial marker gene PpHmpl to a similar extent in both tissues (Fig. 2B). This supports the hypothesis that a compatible plantmicrobe interaction is likely occurring in tissues of different ages. The restriction on pathogen biomass in proximal young tissues (Fig. 5), which was present regardless of aggressiveness of the $P$. palmivora strain, is therefore more likely attributable to an unfavorable tissue environment rather than immune responses that would result in isolate-specific incompatibility. Notably, the resistant variety Manchuria also displayed differences in infection susceptibility in first and third leaves, suggesting that the underlying mechanisms for mature leaf susceptibility act in addition to other variety-specific resistances.

Our data demonstrating MTS contrasts with the well-known but poorly understood phenomenon of age-related resistance (ARR) in plants in which pathogen resistance typically increases with plant age. While there are examples of immunitybased mechanisms for ARR, such as the induction of resistance gene expression in older tissues (Hayden et al. 2004; Lagudah et al. 2006; Segovia et al. 2014), increased resistance also correlates with major developmental transitions. These include floral transitioning (Hugot et al. 1999), fruit ripening (Salzman et al. 1998), and leaf maturity ( $\mathrm{Li}$ and $\mathrm{Xu} 2002$ ), and, therefore, indicate that other processes can be involved. ARR concerning Phytophthora species in particular has been demonstrated previously. Soybean hypocotyl resistance to Phytophthora sojae increases with tissue age (Lazarovits et al. 1981), pepper displays a vegetative phase associated ARR to Phytophthora capsici (Kim et al. 1989), and Nicotiana benthamiana plants become more resistant to $P$. infestans with age (Shibata et al. 2010). However, the data on MTS presented here using the barley- $P$. palmivora system supports an opposite scenario to ARR. Further experiments are required to unravel the molecular basis of this phenomenon and it will be interesting to compare and contrast ARR with MTS in future experiments.

Mutation of Mlo has been shown to confer resistance to B. graminis (Jørgensen 1992) and increase susceptibility to M. oryzae and Ramularia collo-cygni (Jarosch et al. 1999; McGrann et al. 2014). Here, we report the new observation that Mlo has a role in resistance to P. palmivora (Fig. 7). In young, meristem-proximal tissues, the mlo5 mutation attenuates $P$. palmivora infection. The observed within-leaf variation points to an interplay of leaf tissue developmental status and MLO function. Impacts on plant development by MLO have previously been reported in Arabidopsis (AcevedoGarcia et al. 2014) and MLO proteins are also involved in pollen tube reception processes (Kessler et al. 2010). In susceptible barley cv. Baronesse, we found P. palmivora infection induced Mlo expression much more highly in meristem distal leaf tissue than in proximal tissue (Fig. 6B and D). Mlo in mockinoculated tissue was expressed at similar low levels in both proximal and distal parts of the leaf (Fig. 6A and C); therefore, the difference in induction between leaf parts specifically during $P$. palmivora challenge is likely due to the discrepancy in susceptibility that we observed between proximal and distal leaf tissue (Fig. 5A, B, and C). Distal tissue supports greater pathogen colonization and, therefore, expression of defense responses and associated genes (such as Mlo) are higher than in proximal tissue where colonization is limited.

In summary, using a new filamentous microbe-barley infection system, we discovered an important role of tissue maturity status on tissue susceptibility, which is influenced by Mlo. Future experiments should elucidate the importance of tissue maturity in susceptibility to other filamentous leaf pathogens such as $M$. oryzae and should assess the plant developmental and molecular basis for this variation.

\section{MATERIALS AND METHODS}

Plant material and growth conditions.

Barley seeds were germinated for two to three days in the light at room temperature on wet Whatman filter paper after two to three days of stratification in the dark at $4^{\circ} \mathrm{C}$. Seedlings were potted into Levington F2 compost and were grown in a controlled environment room set to a 16-h light and 8-h dark cycle with temperatures of 21 and $19^{\circ} \mathrm{C}$, respectively, a constant $50 \%$ relative humidity, and a light intensity of approximately $350 \mu \mathrm{Mol} \mathrm{m} \mathrm{s}^{-2}$ for 13 to 14 days before harvesting leaves for inoculation assays with $P$. palmivora.

\section{$P$. palmivora transformation and maintenance.}

Fluorescently labeled P. palmivora ARI-td (accession P3914) was generated by transformation of zoospores by electroporation (Huitema et al. 2011) with a pTOR::tdTomato (Chaparro-Garcia et al. 2011) construct to allow tracking of oomycete growth in planta. $P$. palmivora ARI-td was maintained long-term on petri plates of rye sucrose agar (RSA) containing G418 (1.5\% agar, $50 \mu \mathrm{g}$ of G418 per milliliter) in a Conviron growth cabinet set to $25^{\circ} \mathrm{C}$ with constant light conditions. For inoculation assays, a piece of mycelium from the growing edge of a $P$. palmivora ARI-td colony on RSA was transferred to the center of a V8 agar plate, as previously reported for culture of $P$. infestans (Chaparro-Garcia et al. 2011) (1.5\% agar, $50 \mu \mathrm{g}$ of G418 per milliliter). V8 plates were grown for five to seven days to allow for sporulation. Nontransformed $P$. palmivora strains were maintained and cultured for zoospores in the same fashion on RSA and V8 plates but without antibiotics. For barley root and leaf inoculation assays, 5- to 7-day-old plates of $P$. palmivora were flooded with $4^{\circ} \mathrm{C}$ sterile water and were incubated in the light at room temperature for $1 \mathrm{~h}$, to induce release of zoospores. For infection assays, zoospores at a concentration, determined using a hemocytometer, of $5 \times 10^{4}$ or $7 \times 10^{4}$ spores per milliliter for root and leaf assays, respectively, were used.

\section{Leaf infection assays.}

Barley leaves were harvested onto wet tissue paper in $24.5 \times$ $24.5 \mathrm{~cm}$ transparent, plastic Corning dishes (Appleton Woods), secured using cocktail sticks (to analyze the whole leaves, as for data in Figures 4 and 5C), or were cut into pieces approximately $2.5 \mathrm{~cm}$ in length (to analyze meristem-proximal versus 
meristem-distal susceptibility). Sites for inoculation were made by manually wounding the leaf tissue at regularly spaced intervals, using a $10-\mu 1$ pipette tip, either in a $5-\mathrm{cm}$ central region (six inoculation sites), along the whole leaf, or on leaf sections (three inoculation sites). An $8-\mu$ d droplet of $P$. palmivora ARI-td zoospore solution at $7 \times 10^{4}$ spores per milliliter was placed on each wound site. Leaves were incubated at $25^{\circ} \mathrm{C}$ for 3 days before scoring each inoculation site for the extent of pathogen colonization, on a scale of 0 to 4, using a Leica M165 FC stereoepifluorescence microscope with a DSRed filter. Ink infiltration of leaves was conducted with a $1 \%$ solution of Sheaffer Skrip black ink.

Disease scores were calculated as follows and statistical tests for significance were conducted in R (details below).

$$
\text { Leaf disease score }=\frac{\sum \text { scores from each inoculation site }}{\sum \text { max possible scores for all sites }}
$$

\section{Root infection assays.}

Barley seeds were surface sterilized in $70 \%$ ethanol for $5 \mathrm{~min}$ and in $2 \% \mathrm{vol} / \mathrm{vol}$ sodium hypochlorite for $5 \mathrm{~min}$, rinsing once with sterile water between these steps and at least four times afterward. Seeds were stratified, to synchronize germination, on wet Whatman paper in the dark at $4^{\circ} \mathrm{C}$ for 2 to 3 days and were subsequently germinated at room temperature in the dark for 4 days. Seedlings were transferred to $1 \%$ phytoagar (Duchefa) 100 -mm square petri plates (Thermo Scientific), up to six seedlings per plate, and plant roots were covered with $80 \mathrm{~mm}$ diameter circular sheets of 325P cellulose (A.A. Packaging Limited). A 500- $\mu$ I P. palmivora ARI-td zoospore solution at $5 \times 10^{4}$ spores per milliliter was pipetted onto and across all roots. The base of the plates were wrapped in foil to exclude light and plates were placed in a Conviron growth cabinet set at $25^{\circ} \mathrm{C}$ with constant light conditions and were scanned daily for six consecutive days after inoculation, using a flatbed scanner. Roots were scanned for four consecutive days and again on the seventh day. From the scans, roots were scored for development of browning symptoms on a scale of 0 to 4 , indicative of infection and disease progression. A disease score was calculated for each variety as follows and statistical tests for significance were conducted using R (details below).

Root disease score $=\frac{\sum \text { scores of each plant on each day scanned }}{\sum \text { max possible scores for each day scanned }}$

\section{qRT-PCR.}

For qRT-PCR on ARI-td-infected roots, barley roots from different plants were pooled together before extracting RNA. For qRT-PCR on ARI-td-infected leaves, a cork borer (size $5 \mathrm{~mm}$ ) was used to punch out a tissue disc around the inoculated wound site. For analysis of meristem-proximal or meristemdistal infection, RNA was extracted from three pooled leaf discs from the same leaf region. Biological replicates were pooled leaf disc samples from separate plants. RNA from $P$. palmivorainfected barley root and leaf tissue was extracted using the Qiagen RNeasy kit including on-column DNAse treatment, according to the manufacturer's recommendations (Qiagen). cDNA was synthesized using 0.5 to $1 \mu \mathrm{g}$ of total RNA and the Roche Transcriptor first-strand cDNA synthesis kit (Roche). qPCR was performed using Roche Lightcycler 480 DNA SYBR Green I master mix. Reactions were performed in a $10-\mu l$ reaction in triplicate and were run on a Roche LightCycler 480 II machine, using the following program: $5 \mathrm{~min}$ of initial denaturation at $95^{\circ} \mathrm{C}$, then 45 cycles of $10 \mathrm{~s}$ at $95^{\circ} \mathrm{C}, 10 \mathrm{~s}$ at $60^{\circ} \mathrm{C}$, and $10 \mathrm{~s}$ at $72^{\circ} \mathrm{C}$. Primers used in this study are listed in Supplementary Table S3. Primers for $H v E F l \alpha$ were described previously by McGrann et al. (2009). The $2^{-\Delta \mathrm{Ct}}$ method was used to calculate expression levels of $P p E F 1 \alpha$ relative to $H v E F 1 \alpha$ (for a relative indication of pathogen biomass) or of PpHmpl, PpCdc14, or PpPAL1 relative to $P p E F 1 \alpha$ (for expression of pathogen life-stage marker genes) (Livak and Schmittgen 2001).

\section{Statistical analysis.}

All statistical analyses were conducted with R. Nonparametric tests were chosen on the assumption of nonnormality of the data. For comparison of leaf and root disease scores between mlo5 BC Pallas and Pallas barley genotypes, Kolmogorov Smirnov tests were used and $P<0.05$ was considered significant (Fig. 7A and B). For comparison of proximal and distal sections of first, second, and third leaves of barley cv. Baronesse and cv. Manchuria, the Kruskal-Wallis test with Tukey's post hoc test was used and $P<0.05$ was considered significant (Fig. 5A).

\section{Microscopy.}

Confocal microscopy was carried out using a Leica TCS SP8 equipped with $\mathrm{HyD}$ detectors and the following settings: excitation, $561 \mathrm{~nm}$; RFP emission, 570 to $600 \mathrm{~nm}$; chloroplast autofluorescence, 650 to $700 \mathrm{~nm}$; and transmitted light/bright field). Acquisition software was Leica Application Suite $X$ and $20 \times$ or $63 \times$ water immersion objectives were used. Other pictures were taken using a dissecting Leica M165 FC stereoepifluorescence microscope, with a DSRed filter for detection of tdTomato, using the PLANAPO $1.0 \times$ objective, $0.73 \times$ zoom, and Leica Application Suite V4.1 acquisition software.

\section{Trypan blue staining.}

Leaves were stained with trypan blue according to the methods outlined by Peterhansel et al. (1997) and were imaged using a flatbed scanner.

\section{Image processing.}

Pictures of leaves were taken using a Leica M165 FC stereoepifluorescence microscope with a DSRed filter, for detection of tdTomato, or a Nikon COOLPIX P520 camera. Whole-leaf images were acquired as tiles and were merged using Photoshop, with adjustments in brightness and contrast.

\section{ACKNOWLEDGMENTS}

We thank M. Smoker and T. Yunusov for help with Phytophthora palmivora culture and transformation, E. Evangelisti for help with statistics, M. Coffey for providing isolates of P. palmivora, G. S. Baltac for help with initial pre-screening of barley cultivars with $P$. palmivora. This work was supported by the Gatsby Charitable Foundation (RG62472), by the Royal Society (RG69135), and by the European Research Council (ERC-2014STG, H2020, 637537 to S. Schornack)

\section{LITERATURE CITED}

Acevedo-Garcia, J., Kusch, S., and Panstruga, R. 2014. Magical mystery tour: MLO proteins in plant immunity and beyond. New Phytol. 204: 273-281.

Ah Fong, A., and Judelson, H. S. 2003. Cell cycle regulator Cdc14 is expressed during sporulation but not hyphal growth in the fungus-like oomycete Phytophthora infestans. Mol. Microbiol. 50:487-494.

Büschges, R., Hollricher, K., Panstruga, R., Simons, G., Wolter, M., Frijters, A., van Daelen, R., van der Lee, T., Diergaarde, P., Groenendijk, J., Töpsch, S., Vos, P., Salamini, F., and Schulze-Lefert, P. 1997. The barley Mlo gene: A novel control element of plant pathogen resistance. Cell 88:695-705

Chaparro-Garcia, A., Wilkinson, R. C., Gimenez-Ibanez, S., Findlay, K., Coffey, M. D., Zipfel, C., Rathjen, J. P., Kamoun, S., and Schornack, S. 2011. The receptor-like kinase SERK3/BAK1 is required for basal resistance against the late blight pathogen Phytophthora infestans in Nicotiana benthamiana. PLoS One 6:e16608. 
Chen, L., Shiotani, K., Togashi, T., Miki, D., Aoyama, M., Wong, H. L., Kawasaki, T., and Shimamoto, K. 2010. Analysis of the Rac/Rop small GTPase family in rice: Expression, subcellular localization and role in disease resistance. Plant Cell Physiol. 51:585-595.

De Coninck, B., Timmermans, P., Vos, C., Cammue, B. P., and Kazan, K. 2015. What lies beneath: Belowground defense strategies in plants. Trends Plant Sci. 20:91-101.

Drenth, A., and Guest, D. I. 2004. Diversity and management of Phytophthora in Southeast Asia. Australian Centre for International Agricultural Research, Canberra, Australia.

Dufresne, M., and Osbourn, A. E. 2001. Definition of tissue-specific and general requirements for plant infection in a phytopathogenic fungus. Mol. Plant-Microbe Interact. 14:300-307.

Eichmann, R., Schultheiss, H., Kogel, K.-H., and Hückelhoven, R. 2004. The barley apoptosis suppressor homologue Bax inhibitor-1 compromises nonhost penetration resistance of barley to the inappropriate pathogen Blumeria graminis f. sp. tritici. Mol. Plant Microbe Interact. 17:484-490.

Eichmann, R., Bischof, M., Weis, C., Shaw, J., Lacomme, C., Schweizer, P., Duchkov, D., Hensel, G., Kumlehn, J., and Hückelhoven, R. 2010. BAX INHIBITOR-1 is required for full susceptibility of barley to powdery mildew. Mol. Plant Microbe Interact. 23:1217-1227.

Elliott, C., Zhou, F., Spielmeyer, W., Panstruga, R., and Schulze-Lefert, P. 2002. Functional conservation of wheat and rice Mlo orthologs in defense modulation to the powdery mildew fungus. Mol. Plant Microbe Interact. 15:1069-1077.

Ellis, J. G., Rafiqi, M., Gan, P., Chakrabarti, A., and Dodds, P. N. 2009. Recent progress in discovery and functional analysis of effector proteins of fungal and oomycete plant pathogens. Curr. Opin. Plant Biol. 12: 399-405.

Erwin, D. C., and Ribeiro, O. 1996. Phytophthora Diseases Worldwide. American Phytopathological Society, St Paul, MN, U.S.A

Fisher, M. C., Henk, D. A., Briggs, C. J., Brownstein, J. S., Madoff, L. C., McCraw, S. L., and Gurr, S. J. 2012. Emerging fungal threats to animal, plant and ecosystem health. Nature 484:186-194.

Forsberg, L. 1985. Foliar diseases of nursery-grown ornamental palms in Queensland. Australas. Plant Pathol. 14:67-71.

Harris, D., Cardon, J. A., Justin, S., and Passey, A. 1984. Phytophthora palmivora on cultured roots of coconut. Trans. Br. Mycol. Soc. 82:249255.

Harrison, M. J. 1999. Biotrophic interfaces and nutrient transport in plant fungal symbioses. J. Exp. Bot. 50:1013-1022.

Hayden, M. J., Kuchel, H., and Chalmers, K. J. 2004. Sequence tagged microsatellites for the Xgwm533 locus provide new diagnostic markers to select for the presence of stem rust resistance gene $S r 2$ in bread wheat (Triticum aestivum L.). Theor. Appl. Genet. 109:1641-1647.

Hok, S., Attard, A., and Keller, H. 2010. Getting the most from the host: How pathogens force plants to cooperate in disease. Mol. Plant-Microbe Interact. 23:1253-1259.

Hugot, K., Aime, S., Conrod, S., Poupet, A., and Galiana, E. 1999. Developmental regulated mechanisms affect the ability of a fungal pathogen to infect and colonize tobacco leaves. Plant J. 20:163-170.

Huitema, E., Smoker, M., and Kamoun, S. 2011. A straightforward protocol for electro-transformation of Phytophthora capsici zoospores. Methods Mol. Biol. 712:129-135.

Jarosch, B., Kogel, K. H., and Schaffrath, U. 1999. The ambivalence of the barley Mlo locus: Mutations conferring resistance against powdery mildew (Blumeria graminis f. sp. hordei) enhance susceptibility to the rice blast fungus Magnaporthe grisea. Mol. Plant Microbe Interact. 12: 508-514.

Jørgensen, J. H. 1992. Discovery, characterization and exploitation of Mlo powdery mildew resistance in barley. Euphytica 63:141-152.

Kamoun, S., van West, P., de Jong, A. J., de Groot, K. E., Vleeshouwers, V. G., and Govers, F. 1997. A gene encoding a protein elicitor of Phytophthora infestans is down-regulated during infection of potato. Mol. Plant Microbe Interact. 10:13-20.

Kemen, E., Kemen, A. C., Rafiqi, M., Hempel, U., Mendgen, K., Hahn, M., and Voegele, R. T. 2005. Identification of a protein from rust fungi transferred from haustoria into infected plant cells. Mol. Plant-Microbe Interact. 18:1130-1139.

Kessler, S. A., Shimosato-Asano, H., Keinath, N. F., Wuest, S. E., Ingram, G., Panstruga, R., and Grossniklaus, U. 2010. Conserved molecular components for pollen tube reception and fungal invasion. Science 330:968-971.

Kim, Y. J., Hwang, B. K., and Park, K. W. 1989. Expression of age-related resistance in pepper plants infected with Phytophthora capsici. Plant Dis. 73:745-474.

Kølster, P., Munk, L., Stølen, O., and Løhde, J. 1986. Near-isogenic barley lines with genes for resistance to powdery mildew. Crop Sci. 26:903-907.
Kumar, J., Hückelhoven, R., Beckhove, U., Nagarajan, S., and Kogel, K.-H. 2001. A compromised Mlo pathway affects the response of barley to the necrotrophic fungus Bipolaris sorokiniana (Teleomorph: Cochliobolus sativus) and its toxins. Phytopathology 91:127-133.

Lagudah, E. S., McFadden, H., Singh, R. P., Huerta-Espino, J., Bariana, H. S., and Spielmeyer, W. 2006. Molecular genetic characterization of the $L r 34 / Y r 18$ slow rusting resistance gene region in wheat. Theor. Appl. Genet. 114:21-30.

Lazarovits, G., Stössel, R., and Ward, E. W. B. 1981. Age-related changes in specificity and glyceollin production in the hypocotyl reaction of soybeans to Phytophthora megasperma var. sojae. Phytopathology 71 : 94-97.

Li, B., and Xu, X. 2002. Infection and development of apple Scab (Venturia inaequalis) on old leaves. J. Phytopathol. 150:687-691.

Livak, K. J., and Schmittgen, T. D. 2001. Analysis of relative gene expression data using real-time quantitative PCR and the $2^{-\Delta \Delta \mathrm{Ct}}$ method. Methods 25:402-408.

Marcel, S., Sawers, R., Oakeley, E., Angliker, H., and Paszkowski, U. 2010. Tissue-adapted invasion Strategies of the rice blast fungus Magnaporthe oryzae. Plant Cell 22:3177-3187.

Mazaheri-Naeini, M., Sabbagh, S. K., Martinez, Y., Sejalon-Delmas, N., and Roux, C. 2015. Assessment of Ustilago maydis as a fungal model for root infection studies. Fungal Biol-Uk 119:145-153.

McDonald, B. A., and Linde, C. 2002. Pathogen population genetics, evolutionary potential, and durable resistance. Annu. Rev. Phytopathol. 40:349-379.

McGrann, G. R. D., Townsend, B. J., Antoniw, J. F., Asher, M. J. C., and Mutasa-Goettgens, E. S. 2009. Barley elicits a similar early basal defence response during host and non-host interactions with Polymyxa root parasites. Eur. J. Plant Pathol. 123:5-15.

McGrann, G. R. D., Stavrinides, A., Russell, J., Corbitt, M. M., Booth, A., Chartrain, L., Thomas, W. T. B., and Brown, J. K. M. 2014. A trade off between $m l o$ resistance to powdery mildew and increased susceptibility of barley to a newly important disease, Ramularia leaf spot. J. Exp. Bot. 65:1025-1037.

Peterhansel, C., Freialdenhoven, A., Kurth, J., Kolsch, R., and SchulzeLefert, P. 1997. Interaction analyses of genes required for resistance responses to powdery mildew in barley reveal distinct pathways leading to leaf cell death. Plant Cell 9:1397-1409.

Piffanelli, P., Zhou, F. S., Casais, C., Orme, J., Jarosch, B., Schaffrath, U., Collins, N. C., Panstruga, R., and Schulze-Lefert, P. 2002. The barley MLO modulator of defense and cell death is responsive to biotic and abiotic stress stimuli. Plant Physiol. 129:1076-1085.

Pretorius, Z. A., Singh, R. P., Wagoire, W. W., and Payne, T. S. 2000. Detection of virulence to wheat stem rust resistance gene $\mathrm{Sr} 31$ in Puccinia graminis f. sp. tritici in Uganda. Plant Dis. 84:203.

Rafiqi, M., Gan, P. H., Ravensdale, M., Lawrence, G. J., Ellis, J. G., Jones, D. A., Hardham, A. R., and Dodds, P. N. 2010. Internalization of flax rust avirulence proteins into flax and tobacco cells can occur in the absence of the pathogen. Plant Cell 22:2017-2032.

Rey, T., Chatterjee, A., Buttay, M., Toulotte, J., and Schornack, S. 2015 Medicago truncatula symbiosis mutants affected in the interaction with a biotrophic root pathogen. New Phytol. 206:497-500.

Ruiz-Lozano, J. M., Gianinazzi, S., and Gianinazzi-Pearson, V. 1999. Genes involved in resistance to powdery mildew in barley differentially modulate root colonization by the mycorrhizal fungus Glomus mosseae. Mycorrhiza 9:237-240.

Salzman, R. A., Tikhonova, I., Bordelon, B. P., Hasegawa, P. M., and Bressan, R. A. 1998. Coordinate accumulation of antifungal proteins and hexoses constitutes a developmentally controlled defense response during fruit ripening in grape. Plant Physiol. 117:465-472.

Schilling, L., Matei, A., Redkar, A., Walbot, V., and Doehlemann, G. 2014. Virulence of the maize smut Ustilago maydis is shaped by organ-specific effectors. Mol. Plant Pathol. 15:780-789.

Schreiber, C., Slusarenko, A. J., and Schaffrath, U. 2011. Organ identity and environmental conditions determine the effectiveness of nonhost resistance in the interaction between Arabidopsis thaliana and Magnaporthe oryzae. Mol. Plant Pathol. 12:397-402.

Schultheiss, H., Dechert, C., Kogel, K.-H., and Hückelhoven, R. 2002. A small GTP-binding host protein is required for entry of powdery mildew fungus into epidermal cells of barley. Plant Physiol. 128:1447-1454.

Segovia, V., Hubbard, A., Craze, M., Bowden, S., Wallington, E.,, Bryant, R., Greenland, A., Bayles, R., and Uauy, C. 2014. Yr36 confers partial resistance at temperatures below $18^{\circ} \mathrm{C}$ to UK isolates of Puccinia striiformis. Phytopathology 104:871-878.

Sesma, A., and Osbourn, A. E. 2004. The rice leaf blast pathogen undergoes developmental processes typical of root-infecting fungi. Nature 431: 582-586. 
Shibata, Y., Kawakita, K., and Takemoto, D. 2010. Age-related resistance of Nicotiana benthamiana against hemibiotrophic pathogen Phytophthora infestans requires both ethylene- and salicylic acid-mediated signaling pathways. Mol. Plant-Microbe Interact. 23:1130-1142.

Skibbe, D. S., Doehlemann, G., Fernandes, J., and Walbot, V. 2010. Maize tumors caused by Ustilago maydis require organ-specific genes in host and pathogen. Science 328:89-92.

Sukno, S. A., Garcia, V. M., Shaw, B. D., and Thon, M. R. 2008. Root infection and systemic colonization of maize by Colletotrichum graminicola. Appl. Environ. Microbiol. 74:823-832.

Torres, G., Sarria, G., Varon, F., Coffey, M., Elliott, M., and Martinez, G. 2010. First report of bud rot caused by Phytophthora palmivora on African oil palm in Colombia. Plant Dis. 94:1163-1163. van Schie, C. C., and Takken, F. L. 2014. Susceptibility genes 101: How to be a good host. Annu. Rev. Phytopathol. 52:551-581.

Wang, E., Schornack, S., Marsh, J. F., Gobbato, E., Schwessinger, B. Eastmond, P., Schultze, M., Kamoun, S., and Oldroyd, G. E. 2012. A common signaling process that promotes mycorrhizal and oomycete colonization of plants. Curr. Biol. 22:2242-2246.

Wang, Y., Cheng, X., Shan, Q., Zhang, Y., Liu, J., Gao, C., and Qiu, J.-L. 2014 Simultaneous editing of three homoeoalleles in hexaploid bread wheat confers heritable resistance to powdery mildew. Nat. Biotechnol. 32:947-951.

Wolter, M., Hollricher, K., Salamini, F., and Schulze-Lefert, P. 1993. The mlo resistance alleles to powdery mildew infection in barley trigger a developmentally controlled defence mimic phenotype. Mol. Gen. Genet. 239:122-128 